\title{
Author Correction: The Mobility Enhancement of Indium Gallium Zinc Oxide Transistors via Low- temperature Crystallization using a Tantalum Catalytic Layer
}

\author{
Yeonwoo Shin ${ }^{1}$, Sang Tae Kim ${ }^{1}$, Kuntae Kim², MiYoung Kim², Saeroonter Oh $\mathbb{D}^{3}$ \& Jae Kyeong \\ Jeong (1) ${ }^{1}$
}

Correction to: Scientific Reports https://doi.org/10.1038/s41598-017-11461-0, published online 07 September 2017

This Article contains an error in the Acknowledgements section.

“This study was supported by the Industrial Strategic Technology Development Program funded by MKE/KEIT under Grant 10048560 and by a National Research Foundation (NRF) grant funded by the Korean government (NRF-2015R1A2A2A01003848)."

should read:

“This study was supported by the Industrial Strategic Technology Development Program funded by MKE/KEIT under Grant 10051403 and by a National Research Foundation (NRF) grant funded by the Korean government (NRF-2015R1A2A2A01003848)."

(i) Open Access This article is licensed under a Creative Commons Attribution 4.0 International License, which permits use, sharing, adaptation, distribution and reproduction in any medium or format, as long as you give appropriate credit to the original author(s) and the source, provide a link to the Creative Commons license, and indicate if changes were made. The images or other third party material in this article are included in the article's Creative Commons license, unless indicated otherwise in a credit line to the material. If material is not included in the article's Creative Commons license and your intended use is not permitted by statutory regulation or exceeds the permitted use, you will need to obtain permission directly from the copyright holder. To view a copy of this license, visit http://creativecommons.org/licenses/by/4.0/.

(C) The Author(s) 2018

\footnotetext{
${ }^{1}$ Department of Electronic Engineering, Hanyang University, Seoul, 133-791, Republic of Korea. ${ }^{2}$ Department of Materials Science and Engineering, Seoul National University, Seoul, 151-742, Republic of Korea. ${ }^{3}$ Division of Electrical Engineering, Hanyang University, Ansan, Gyeonggi-do, 15588, Korea. Correspondence and requests for materials should be addressed to S.O. (email: sroonter@hanyang.ac.kr) or J.K.J. (email: jkjeong@hanyang.ac.kr)
} 